\title{
VENOMOUS SNAKEBITES AND ANTIVENOM TREATMENT ACCORDING TO A PROTOCOL FOR PEDIATRIC PATIENTS IN TAIWAN
}

\author{
Wang JD (1, 2), Tsan YT (3), Yan-Chiao Mao (3), Wang LM (3, 4, 5)
}

(1) Division of Pediatric Emergency, Taichung Veterans General Hospital, Taichung, Taiwan, Republic of China; (2) Institute of Biochemistry and Biotechnology, Chung San Medical University, Taichung, Taiwan, Republic of China; (3) Department of Emergency Medicine, Taichung Veterans General Hospital, Taichung, Taiwan, Republic of China; (4) Division of Emergency Medicine, National Yang-Ming University, Taipei, Taiwan, Republic of China; (5) Graduate Institute of Health Care Organization, National Taiwan University, Taipei, Taiwan, Republic of China

ABSTRACT: Children bitten by venomous snakes comprise emergency cases that present high morbidity and mortality, especially in some regions of Asia and Africa. Reports on clinical features and management of envenomated children are scarce. This observational study implemented a protocol for antivenom use in pediatric snakebite victims in Taiwan, between 1994 and 2007. The present work investigated demographics, clinical features and effects of antivenom therapy and the complications and prognosis for snakebites. A total of 55 children and adolescents, with a median age of 9.9 years (ranging from 2 to 18 years), was identified. Forty-five patients (82\%) were bitten between May and September. Thirty-five patients (64\%) received antivenom therapy, 28 of them ( $80 \%)$ within two hours after being bitten. No fatalities occurred and only five of 35 patients (14\%) had major morbidity when treated according to the protocol. Thirty-one snakes (56\%) were identified and 12 of them (38\%) were Naja atra. This study indicates that a protocol for children affected by snakebites is valuable for guiding emergency physicians to treat these patients immediately. Further strategies are required to reduce the morbidity rate that occurs as a result of Naja atra bite.

KEY WORDS: snakebites, children, antivenom.

CONFLICTS OF INTEREST: There is no conflict.

\section{CORRESPONDENCE TO:}

LEE-MING WANG, Department of Emergency Medicine, Taichung Veterans General Hospital, Taichung, Taiwan, Republic of China. Phone: 8864 23592525, ext. 5929. Fax: 8864 2374-1359. Email: jiaander@vghtc.gov.tw. 


\section{INTRODUCTION}

Snakebite injuries are not uncommon in Asia (1-4). However, reports of their clinical features and management in children are scarce, even in countries known to present a high snakebite incidence $(5,6)$. In Taiwan, despite rapid urbanization, snakebites occur often in adults who work on farms, in fields and in forests (7). However, as the habitats of snake species often overlap with human environments, children are occasionally bitten by snakes (8). Venomous snakebites are fatal for small animals but are generally not lethal in humans. However, the same amount of venoms affects children more severely than adults $(9,10)$. Therefore, research into the management of venomous snakebites in children is crucial. A protocol for snakebite management had been applied to pediatric patients with snakebites in our institutes. We investigated the clinical features, antivenom management, complications and prognoses for snakebites in children.

\section{PATIENTS AND METHODS}

\section{Protocol of Snakebite Management}

Snakebite patients brought to the pediatric emergency unit were registered, then evaluated and treated according to the protocol (Figure 1). The key points in the protocol are listed below. No envenomation was characterized by the presence of fang marks without local swelling or systemic reaction, including paresthesias, nausea and vomiting, and muscle weakness. If there was no symptom or sign of envenomation during the initial survey, patients were kept under observation for more than 6 hours (24 hours if bitten by Bungarus multicinctus). No antivenom was administered to these non-envenomated patients and outpatient follow-up was arranged. 


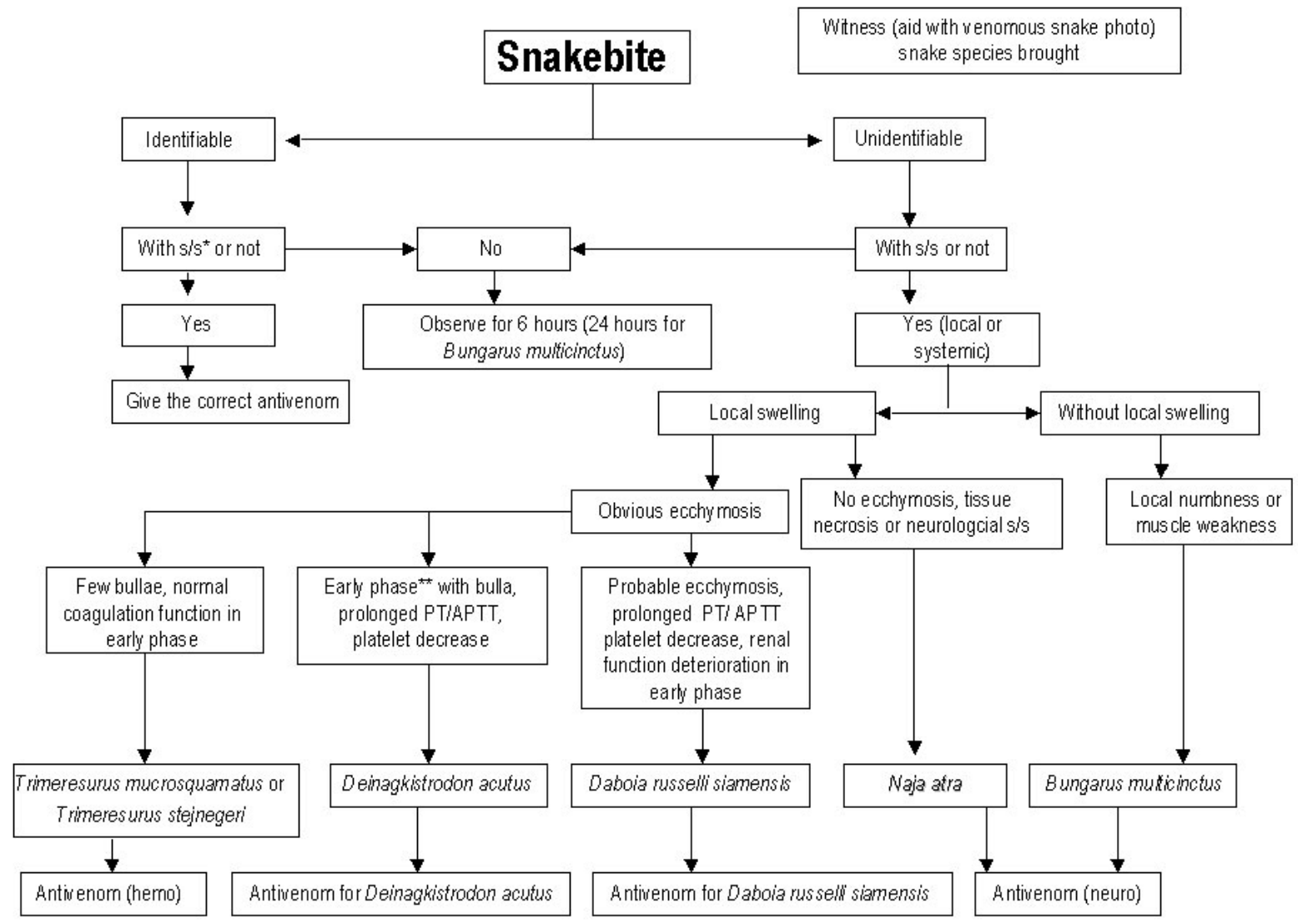

*Symptoms and signs; **30 to 60 minutes after the bite; PT: prothrombin time; APPT: activated partial prothrombin time.

Figure 1. Flow chart of snakebite management in children from the Foundation for Poison Control of Taiwan (with modification).

We used four types of antivenom, including against neurotoxic and hemotoxic venoms, anti-Deinagkistrodon acutus and anti-Daboia russelli siamensis which were all produced at the Vaccine Center, Centers for Disease Control, in Taiwan, since the 1980's. The antivenom used (freeze-dried vial) was an enriched solution of $F\left(a b^{\prime}\right)_{2}$ immunoglobulin obtained from horses immunized with a mixture of venom from the species, and yielded by a pepsin digestion approach. Each vial contained 1000 Tanaka units of freeze-dried $F\left(a b^{\prime}\right)_{2}$. According to the manufacturer each unit of reconstituted antivenom neutralizes $8 \mu \mathrm{g}$ of reference venoms from species of mice (11). It was prescribed according to snake identification or based on clinical symptoms and signs for unidentifiable snakes. All patients were pretreated with $1 \mathrm{mg} / \mathrm{kg}$ (maximum $30 \mathrm{mg}$ ) of diphenhydramine and $2.5 \mathrm{mg} / \mathrm{kg}$ of hydrocortisone (maximum $100 \mathrm{mg}$ ) intravenously $(12,13)$. The freeze-dried antivenom was diluted with 50-100 $\mathrm{mL}$ of normal saline and infused intravenously for one hour. The dosage most toxicologists used for treating pediatric patients with snakebites was the same as that for adults. In general, 6-12 vials of antivenom against neurotoxic venom were used for Naja atra bite and two vials for Bungarus multicinctus; one vial of antivenom against hemotoxic venom was used for Trimeresurus stejnegeri and one vial for Trimeresurus 
mucrosquamatus; two vials of anti-Deinagkistrodon acutus were used for Deinagkistrodon acutus and 2-4 vials of anti-Daboia russelli siamensis were used for Daboia russelli siamensis bite. During the infusion, the blood pressure, consciousness and skin reaction were evaluated. Total dosage and time from bite to first dose of antivenom were analyzed. A repeat dose was administered if there was progression to local swelling, ecchymoses or gangrene or if systemic symptoms/signs occurred one hour after the first dose.

\section{Study Population and Clinical Features}

Snakebite patients aged less than 18 years, registered from 1994 to 2007, were reviewed. Data for patient age, gender, bite time, body part bitten, locality and snake species were included. The identification of snake species was primarily based on the specimen the family brought to the hospital or on recognition using snake photographs (Figure 2).
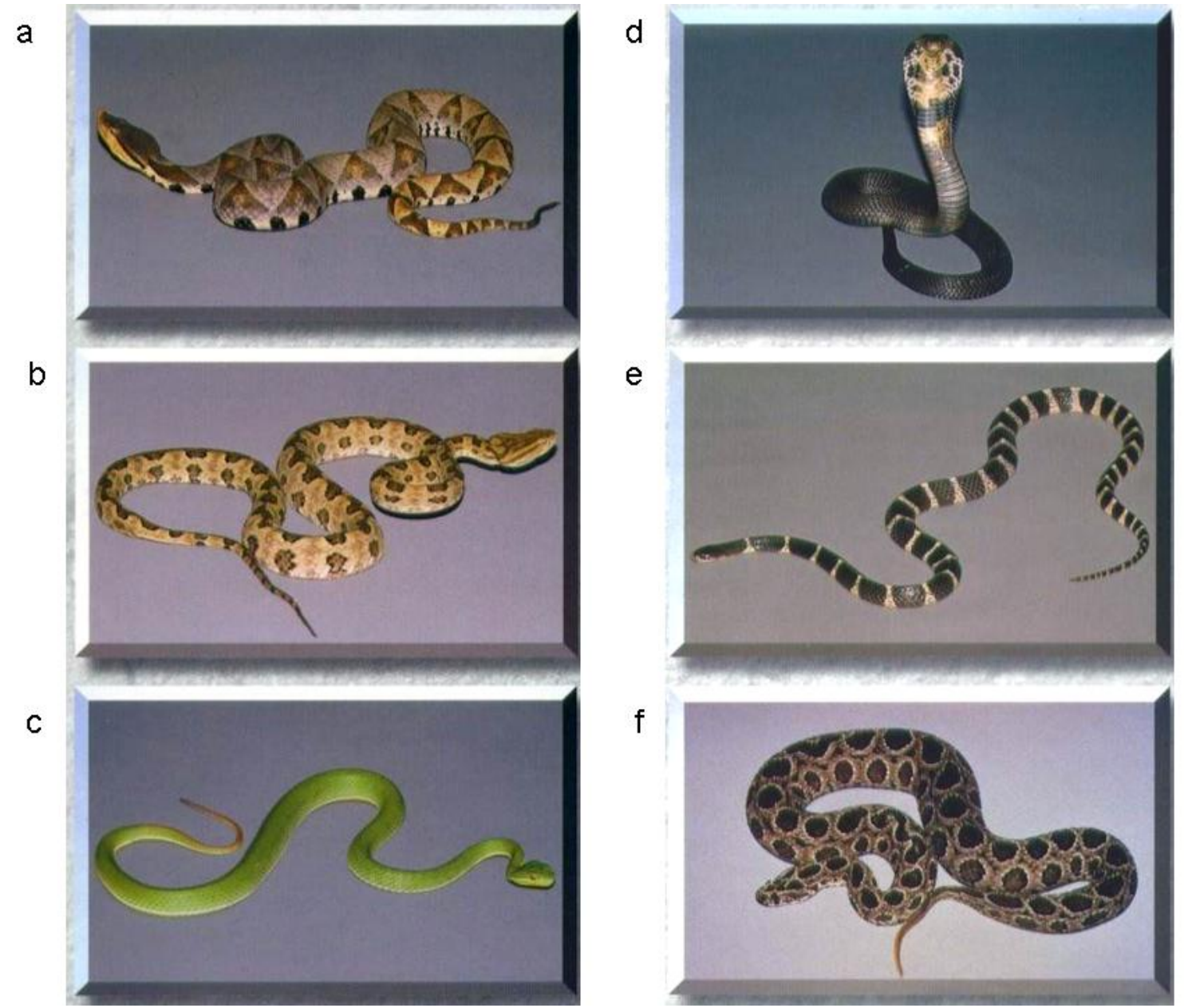

Figure 2. Six most common venomous snakes in Taiwan: (a) Deinagkistrodon acutus; (b) Trimeresurus mucrosquamatus; (c) Trimeresurus stejnegeri; (d) Naja atra; (e) Bungarus multicinctus; and (f) Daboia russelii siamensis (photos by the Foundation for Poison Control of Taiwan). 


\section{Complications and Prognosis}

Complications after snakebite were investigated and included respiratory failure, hemodynamic instability, systemic reaction after antivenom use and need for surgery. In addition, functional impairment of the bitten limb during follow-up and mortality rate were addressed.

\section{RESULTS}

Demographic and Clinical Features

A total of 55 patients, 44 males and 11 females, were identified in this study. Their ages ranged from 2 to 18 years with a median of 9.9 years. All patients were initially brought to the pediatric emergency unit with fang marks. Their demographics, time and locality of bite, body part bitten and the interval from bite to hospital arrival are summarized in Table 1. Of 55 patients, 45 were bitten from May to September and in 25 of 37 patients the bites occurred at or near home. Five patients were bitten by captive snakes. Eighty-seven percent of patients (48/55) were taken to the hospital within three hours after the attack. 
Table 1. Demographic and clinical features of children with snakebites $(n=55)$

\begin{tabular}{|c|c|}
\hline Gender - male:female & $41: 14$ \\
\hline Age (years) & $9.9(2-18)^{*}$ \\
\hline \multicolumn{2}{|l|}{ Bite months } \\
\hline May-September & 45 \\
\hline Others & 10 \\
\hline \multicolumn{2}{|l|}{ Bite hours } \\
\hline 6:00-12:00 & 7 \\
\hline $12: 00-18: 00$ & 23 \\
\hline $18: 00-24: 00$ & 22 \\
\hline 24:00-6:00 & 3 \\
\hline \multicolumn{2}{|l|}{ Locality of snakebite $(n=37)$} \\
\hline home/yard & 25 \\
\hline Field & 5 \\
\hline Waterside & 5 \\
\hline Others & 2 \\
\hline \multicolumn{2}{|l|}{ Bite site $(n=55)$} \\
\hline Foot & 29 \\
\hline Hand & 22 \\
\hline Others & 4 \\
\hline Time to hospital arrival (hours) & $1.5(0.5-24)$ \\
\hline
\end{tabular}

*Data expressed as median (range).

\section{Envenomation and Laboratory Data}

The clinical symptoms and signs of 35 patients with envenomation are listed in Table 2. The most common presentations of Naja atra bite were swelling of the bitten part, nausea and vomiting, and progressive pain. The five cases with tissue necrosis all resulted from Naja atra bite. Local ecchymoses were found in patients bitten by hemotoxotic snakes (Trimeresurus).

The laboratory data revealed that the mean leukocyte count $\left(10243 \pm 3382 / \mathrm{mm}^{3}\right), \mathrm{Hb}$ level $(13.5 \pm 1.6 \mathrm{~g} / \mathrm{dl})$, and platelet count $\left(279 \pm 100 \times 10^{3} / \mathrm{mm}^{3}\right)$ were within normal 
range. The patient with a Deinagkistrodon acutus bite presented with decreased platelet count $\left(140 \times 10^{3} / \mathrm{mm}^{3}\right)$, prolonged PT $(14.5 \mathrm{sec})$ and APTT $(38.1 \mathrm{sec})$, and an elevated Creatine Kinose level (1539 IU/L). Six patients bitten by Trimeresurus had slightly prolonged APTT with a mean of $38 \mathrm{sec}$ (ranging from 35-44).

Table 2. Symptoms and signs of envenomated patients on hospital presentation $(n=$ 35)

\begin{tabular}{|c|c|c|c|c|c|c|c|c|}
\hline $\begin{array}{l}\infty \\
\frac{0}{U} \\
\Phi \\
\frac{0}{0} \\
\infty \\
0 \\
\frac{1}{0} \\
\frac{1}{\omega} \\
\omega\end{array}$ & 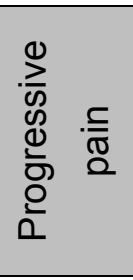 & 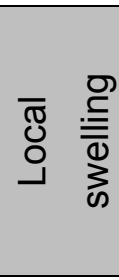 & 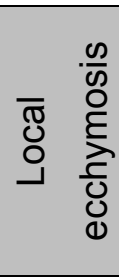 & $\frac{\widetilde{\sigma}}{\overline{\bar{D}}}$ & 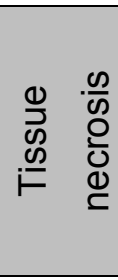 & 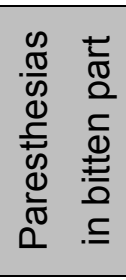 & 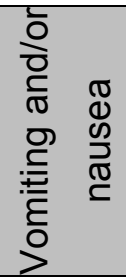 & $\begin{array}{l}\frac{\infty}{D} \\
\frac{0}{0}\end{array}$ \\
\hline $\begin{array}{c}\text { Naja atra } \\
(\mathrm{n}=11)\end{array}$ & 5 & 8 & 0 & 0 & 4 & 2 & 6 & 2 \\
\hline $\begin{array}{l}\text { T. stejnegeri } \\
\quad(\mathrm{n}=7)\end{array}$ & 1 & 4 & 4 & 1 & 0 & 0 & 0 & 0 \\
\hline $\begin{array}{l}\text { T. mucrosquanmatus } \\
\qquad(\mathrm{n}=5)\end{array}$ & 4 & 4 & 2 & 1 & 0 & 0 & 0 & 0 \\
\hline $\begin{array}{l}\text { Deinagkistrodon acutus } \\
\qquad(\mathrm{n}=1)\end{array}$ & 1 & 1 & 0 & 1 & 0 & 0 & 0 & 0 \\
\hline \multicolumn{9}{|l|}{ Unidentified } \\
\hline $\begin{array}{l}\text { Neurotoxic snakes } \\
\qquad(n=3)\end{array}$ & 1 & 2 & 0 & 0 & 1 & 1 & 3 & 1 \\
\hline $\begin{array}{l}\text { Hemotoxic snakes } \\
\qquad(\mathrm{n}=8)\end{array}$ & 1 & 5 & 7 & 1 & 0 & 0 & 0 & 0 \\
\hline
\end{tabular}

\section{Antivenom Therapy}

Among 55 venomous snakebites, 31 snake species were identifiable. Of these 31 identifiable snakes, 20 were determined by snake specimens brought to the emergency department and the other identifications were based on viewing of photographs. Thirty-five patients (64\%) were given antivenom and 28 of the 35 received it within 2 hours after being bitten (Table 3). Of these 35 children, 11 were attended first at a local hospital and then transferred to our emergency department. Among 24 unidentifiable snakes, 11 were administered antivenom, eight hemotoxic antivenom and three neurotoxic antivenom. At least one repeat dose was given to four patients with Trimeresurus mucrosquamatus bites, 5 Trimeresurus stejnegeri, 4 Naja atra and two unidentifiable snakes. The reasons for giving these 15 patients repeat doses were failure to achieve primary controls and progression of symptoms. The total 
dosage of antivenom used is listed in Table 3.

Of 11 patients with envenomation after having been bitten by Naja atra, the mean dosage of antivenom used was 7.8 (range 3 to 12) vials in five patients who were submitted to surgery, compared with 3.0 (range 2 to 4 ) vials in the others who did not undergo surgery. A larger dose was given to patients with high grades of envenomation, who might later experience major complications and require surgery.

Table 3. Antivenom treatment and complications of children bitten by snakes $(n=35)$

\begin{tabular}{c|c|c|c|c}
\hline Snake species & $\begin{array}{c}\text { Antivenom } \\
\text { use }(\mathrm{n})\end{array}$ & $\begin{array}{c}\text { Time to antivenom } \\
\text { use }(\mathrm{h})\end{array}$ & Dose (bottle) & Complications \\
$\begin{array}{c}\text { Naja atra } \\
(\mathrm{n}=12)\end{array}$ & 11 & $2.1(0.5-5)^{*}$ & $5.5(2-12)$ & $\begin{array}{c}3 \text { fasciotomies; 1 debridement; } \\
1 \text { flap reconstruction }\end{array}$ \\
\hline $\begin{array}{c}\text { T. stejnegeri } \\
(\mathrm{n}=10)\end{array}$ & 7 & $1.3(0.5-3)$ & $4.2(1-11)$ & None \\
\hline $\begin{array}{c}\text { T. mucrosquanmatus } \\
(\mathrm{n}=6)\end{array}$ & 5 & $2.0(1-4)$ & $4.4(4-6)$ & None \\
\hline $\begin{array}{c}\text { Bungarus multicinctus } \\
(\mathrm{n}=2)\end{array}$ & 0 & - & - & None \\
\hline $\begin{array}{c}\text { Deinagkistrodon acutus } \\
(\mathrm{n}=1)\end{array}$ & 1 & 1 & 5 & None \\
\hline $\begin{array}{c}\text { Unidentified } \\
(\mathrm{n}=24)\end{array}$ & & $3.5(1-24)$ & $3.0(1-4)$ & $4.5(4-5)$ \\
\hline Neurotoxic snakes & 3 & $2.0(2-11)$ & & None \\
\hline Hemotoxic snakes & 8 & & & \\
\hline
\end{tabular}

${ }^{*}$ Data expressed as mean (range).

\section{Adverse Effects and Complications}

Among the 35 patients treated with antivenom, only three patients developed skin rash; all three recovered soon after being given repeated doses of diphenhydramine and hydrocortisone. None had severe allergic reaction. In addition, no patients needed intubation or limb amputation and none had occurrence of shock or disseminated intravascular coagulopathy. Despite early use of antivenom, five patients needed surgery due to compartment syndrome (three patients), gangrene (one patient) or tissue necrosis (one patient). All five of these patients were bitten by Naja atra. 


\section{DISCUSSION}

Snakebites constitute one of the major causes of morbidity and mortality in developing countries (14-16). Because the habitats of snake species often overlap with human environments, children are occasionally found with snakebites even in highly urbanized countries. Its importance as an emergency medical condition is high among children. Although case series from the USA, South America, Australia and Asia have reported children with snakebites, they show different snake species from Taiwan (17-22). In addition, high mortality and functional impairment of extremities after bites were found in some studies due to delayed hospital visits and limited antivenom use $(14,16)$. Among more than 40 terrestrial snake species in Taiwan, 6 venomous snakes are responsible for most clinically important bites. The 6 species, Naja atra and Bungarus multicinctus (Elapidae), and Deinagkistrodon acutus, Trimeresurus mucrosquamatus, Trimeresurus stejnegeri and Daboia russelii siamensis (Viperidae), differ in habits, habitat characteristics, and in their venom potency and lethality (7). The study points out that a protocol for children with snakebites is valuable for guiding an emergency physician to manage these patients immediately.

In the 1980's, $F\left(a b{ }^{\prime}\right)_{2}$ type antivenom was produced using a pepsin digestion approach at the Centers for Disease Control, in Taiwan, and made universally available to primary and secondary hospitals (11). Therefore, most envenomated patients could be promptly treated within a few hours of being bitten. In addition, the first snakebite poison consultation center in Taiwan was established at Taipei Veterans General Hospital in 1986 to provide clinical physicians with round-the-clock poisoning consultation on how to correctly diagnose snakebites and treat them with the appropriate antivenom. The establishment of this center greatly improves the propagation of knowledge on snakebite treatment, and has resulted in favorable outcomes after poisonous snakebites in Taiwan.

Antivenom is the most effective treatment for snakebite envenomation, but the use of such immunoglobulins has the potential to cause anaphylaxis. As a result, prophylactic treatments including combinations of adrenaline, antihistamines and/or corticosteroids have been used concurrently with antivenom since the 1960's $(12,13)$. The protocol we used was devised in 1994, and included premedication with $\mathrm{H} 1$-antihistamine and hydrocortisone before antivenom administration. Although few patients presented skin rash, no anaphylaxis occurred in these 35 patients. However, in the last decade, studies of the efficacy and safety of premedication strategies have been conducted in Sri Lanka and Brazil (23, 24). Subcutaneous adrenaline premedication produced a significant reduction in the incidence of early adverse reactions, and the effect was preserved when stratified for severity (23). But antihistamine appears to be of no obvious benefit in preventing acute reactions from antivenom (24). There is also no good evidence that hydrocortisone should be given 
before antivenom (25).

The identification of snake species is important if antivenom is to be used. However, the species is not ably identified if the patient or companion fails to see or catch the responsible snake. Some reports in adults indicate that these cases account for up to $30 \%$ of the total number (7). In children, this phenomenon would be more frequent, as found in the present study, because of a lesser ability to clearly describe the features of a snake or catch it successfully. Although these unidentifiable snakes could be non-venomous, venomous species are not uncommon. Therefore, guidelines for snakebite identification based on clinical symptoms and laboratory analysis is important to improve clinical diagnosis of snakebites (26). In addition, we suggest implementing a treatment protocol that is specific to the snake species of the local area.

Naja atra venom is composed of many proteins that exert neurotoxic, cardiotoxic, and hemotoxic properties. The mainstay of treatment for cobra envenomation is aggressive supportive care (mechanical ventilation and hemodynamic support) and the administration of antivenom (27). Of 12 patients bitten by Naja atra, only one did not receive antivenom therapy because of absence of envenomation. Among 11 patients administered antivenom, none developed early or late neurological or cardiogenic side effects after early use of antivenom. However, five patients needed surgical intervention subsequently despite an antivenom dose higher than those given to patients not requiring surgery. Although the use of antivenom is indicated for systemic manifestations of envenomation such as the development of neurotoxicity or cardiotoxicity, the question of whether the increased dosage or early administration of antivenom for Naja atra bites is beneficial for preventing not only the abovementioned systemic reaction but also tissue injuries requires further study $(27,28)$.

\section{Limitations}

Antivenom treatment was found to be related to a decline in the fatality rate (19). However, the dose of antivenom for children with envenomation has been the subject of much debate (15). Published studies have indicated that the same venom is injected in both children and adults after being bitten. Logic suggests that the antivenom dosage for neutralizing the venom should be equivalent in children and adults (29). To the best of our knowledge, no study provided the rational dose for pediatric patients with snakebites before our protocol was used. In this study, the dosage toxinologists used for treating pediatric patients with snakebites was not standardized. Moreover, a rational dosage according to envenomation severity could not be addressed. In addition, the protocol did not include a specific method for repeat dosing, specific laboratory data or follow-up. Although the limited data show that the antivenom dose in adults is safe and effective for use in children, randomized 
controlled trials are needed to address antivenom treatment doses in children with snakebites according to envenomation grade.

\section{CONCLUSIONS}

The study shows that treatment for pediatric patients with snakebites according to the protocol normally does not result in fatalities and there is only a small percentage of major injuries that occur as a result of Naja atra bite. Determining the rational dosage for pediatric patients with snakebites requires larger randomized controlled trials. Moreover, additional strategies are needed to reduce the number of morbidity cases in patients bitten by Naja atra.

\section{ACKNOWLEDGEMENTS}

The authors are grateful to the Foundation for Poison Control of Taiwan for its kind support in providing photographs of snakes.

\section{REFERENCES}

1. Viravan C, Looareesuwan S, Kosakarn W, Wuthiekanum V, McCarthy CJ, Stimson AF, Bunnag D, Harinasuta T, Warrell DA. A national hospital-based survey of snakes responsible for bites in Thailand. Trans R Soc Trop Med Hyg. 1992;86(1):100-6.

2. Pandey DP. Epidemiology of snakebites based on field survey in Chitwan and Nawalparasi districts, Nepal. J Med Toxicol. 2007;3(4):164-8.

3. Hutton RA, Looareesuwan S, Ho M, Silamut K, Chanthavanich P, Vejcho S, et al. Arboreal green pit vipers (genus Trimeresurus) of south-east Asia: bites by $T$. albolabris and T. macrops in Thailand and a review of the literature. Trans $\mathrm{R}$ Soc Trop Med Hyg. 1990;84(6):866-74.

4. Bhardwaj A, Sokhey J. Snake bites in the hills of north India. Natl Med J India. 1998;11(6):264-5.

5. Dumavibhat B. A study of epidemiology, risk factors and preventive measures against snake bites. J Med Assoc Thai. 1997;80(9):547-56.

6. Mitrakul C. Clinical features of viper bites in 72 Thai children. Southeast Asian $\mathrm{J}$ Trop Med Public Health. 1982;13(4):628-36.

7. Hung DZ. Taiwan's venomous snakebite: epidemiological, evolution and geographic differences. Trans R Soc Trop Med Hyg. 2004;98(2):96-101.

8. Hon KL, Kwok LW, Leung TF. Snakebites in children in the densely populated city of Hong Kong: a 10-year survey. Acta Pediatr. 2004;93(2):270-2.

9. Chippaux JP. Local complications of snake bites. Med Trop. 1982;42:177-83.

10. Ozay G, Bosnak M, Ece A, Davutoglu M, Dikici B, Gurkan F, et al. Clinical characteristics of children with snakebite poisoning and management of complications in the pediatric intensive care unit. Pediatr Int. 2005;47(6):669-75. 
11. Liau MY, Huang RJ. Toxoids and antivenoms of venomous snakes in Taiwan. J Toxicol. 1997;16(3):163-75.

12. Sutherland SK. Treatment of snake bite in Australia and Papua New Guinea. Aust Fam Physician. 1976;5(3):272-88.

13. Tibballs J. Premedication for snake antivenom. Med J Aust. 1994;160(1):4-7.

14. Adhisivam B, Mahadevan S. Snakebite envenomation in India: a rural medical emergency. Indian Pediatr. 2006;43(6):553-4.

15. Simpson ID. The pediatric management of snakebite the national protocol. Indian Pediatr. 2007;44(3):173-6.

16. Bawaskar HS, Bawaskar PH. Envenoming by the common krait (Bungarus caeruleus) and Asian cobra (Naja naja): clinical manifestations and their management in a rural setting. Wilderness Environ Med. 2004;15(4):257-66.

17. Matteucci MJ, Hannum JE, Riffenburgh RH, Clark RF. Pediatric sex group differences in location of snakebite injuries requiring antivenom therapy. J Med Toxicol. 2007;3(3):103-6.

18. Cruz NS, Alvarez RG. Rattlesnake bite complications in 19 children. Pediatr Emerg Care. 1994;10(1):30-3.

19. Shaw BA, Hosalkar HS. Rattlesnake bites in children: antivenom treatment and surgical indications. J Bone Joint Surg Am. 2002;84(9):1624-9.

20. Bucaretchi F, Herrera SR, Hyslop S, Baracat EC, Vieira RJ. Snakebites by Crotalus durissus ssp in children in Campinas, São Paulo, Brazil. Rev Inst Med Trop São Paulo. 2002;44(3):133-8.

21. Litovitz TL, Klein-Schwartz W, White S, Cobaugh DJ, Youniss J, Omslaer JC, et al. 2000 Annual report of the American Association of Poison Control Centers Toxic Exposure Surveillance System. Am J Emerg Med. 2001;19(5):337-95.

22. Amin MR, Mamun SMH, Rashid R, Rahman M, Ghose A, Sharmin S, et al. Anti-snake venom: use and adverse reaction in a snake bite study clinic in Bangladesh. J Venom Anim Toxins incl Trop Dis. 2008;14(4):660-72.

23. Premawardhena AP, de Silva CE, Fonseka MMD, Gunatilake SB, de Silva HJ. Low dose subcutaneous adrenaline to prevent acute adverse reactions to antivenom serum in people bitten by snakes: randomised, placebo controlled trial. Br Med J. 1999;318(7190):1041-3.

24. Fan HW, Marcopito LF, Cardoso JLC, França FOS, Malaque CMS, Ferrari RA, Theakston RDG, Warrell DA. Sequential randomised and double blind trial of promethazine prophylaxis against early anaphylactic reactions to antivenom for Bothrops snake bites. Br Med J. 1999;318(7196):1451-3.

25. Nuchpraryoon I, Garner P. Interventions for preventing reactions to snake antivenom. Cochrane Database Syst Rev. 2000;(2):CD002153. 
26. Gold BS, Dart RC, Barish RA. Bites of venomous snakes. N Engl J Med. 2002;347(5):347-56.

27. Britt A, Burkhart K. Naja naja cobra bite. Am J Emerg Med. 1997;15(5):529-31.

28. Gold BS. Neostigmine for the treatment of neurotoxicity following envenomation by the Asiatic cobra. Ann Emerg Med. 1996;28(1):87-9.

29. Theakston R, Phillips R, Warrell D, Galagedera Y, Abeysekera D, Dissanayaka P, de Silva A, Aloysius D. Envenoming by the common krait (Bungarus caeruleus) and Sri Lankan cobra (Naja naja naja): efficacy and complications of therapy with Haffkine antivenom. Trans R Soc Trop Med Hyg. 1990;84(2):301-8. 